et al's earlier research (1990) showed UK Hindus had higher rates than Moslems. It would be interesting to know if their later work finds this pattern repeated.

Durk heim, E. (1952) Suicide. London: Routledge and Kegan Paul. Glover, G. R. (1990) The mental health of Asians in Britain. British Medical Journal, 301, 239-240.

INEICHEN, B. (1993) Responding to adversity: mental illness, religion and social change among British Asians. In Religion and Ethnicity: Minorities and Social Change in the City (ed. R. Barot). Kok Pharos.

Soni Raleigh, V. S., Bulusu, L. \& Balarajan, R. (1990) Suicides among immigrants from the Indian subcontinent. British Journal of Psychiatry, 156, 46-50.

Department of Public Health/Epidemiology Charing Cross and Westminster Medical School 17 Horseferry Road

London SWIP 2AR

AUTHOR'S REPLY: Dr Ineichen raises a valid issue. Aggregation of groups originating from the Indian subcontinent conceals the significant epidemiological differences that exist between them, and our preference would have been to disaggregate into the different national, religious and regional subgroups. We have always adopted this approach where possible, as for instance in an earlier paper in which we were able to examine religious differences in suicide rates (Soni Raleigh et al, 1990). Some disaggregation was feasible on that occasion because we were in the unusually fortunate position of working directly from death certificates, and hence could distinguish between Hindu and Muslim names.

Unfortunately, much of the epidemiological research relating to ethnic minorities has been constrained because the data more typically available (on mortality and population size) do not permit such disaggregation. We did not have access to the death certificates for this later period. Instead, we used the OPCS national mortality data relating to persons born in the Indian subcontinent. These cannot be disaggregated into the component country groups (India, Pakistan, Bangladesh, Sri Lanka) without some bias - the reason for the bias is that India is sometimes referred to as undivided, prepartition India in recording country of birth at the time of death registration. Thus, deaths registered as Indian-born include some people born in Pakistan. It is for this reason that OPCS have followed the practice of aggregating the groups from the Indian subcontinent (Marmot et al, 1984) and the subject is discussed in greater detail in these publications. Hence, in this paper, we were not able to examine any subgroups, whether national, regional or religious, and I am conscious that we thereby lose an important dimension to the work. In the circumstances, it was unavoidable. I have little doubt (although this is no more than an informed hunch) that the pattern vis-àvis Hindu and Muslim suicide rates would be similar to what other studies have shown, because, as $\mathrm{Dr}$ Ineichen points out, the two religions have very different positions on suicide.

Son Raleigh, V., Bulusu, L. \& Balarajan, R. (1990) Suicides among immigrants from the Indian sub-continent. British Journal of Psychiatry, 156, 46-50.

Marmor, M. G., Adelsten, A. M. \& Bulusu, L. (eds) (1984) Immigrant Mortality in England and Wales, 1970-78: Causes of Death by Country of Birth. Studies on Medical and Population Subjects no. 47. OPCS. London: HMSO.

Institute of Public Health

VeEna Soni Raleigh

University of Surrey

Guildford

Surrey GU2 57L

\section{What is the incidence of conversion pseudodementia?}

SIR: Copeland et al (Journal, August 1992, 161, 230 239) presented a three-year follow-up study designed to confirm the prevalence and incidence of dementia, depression, and pseudodementia identified in a sample of 1070 elderly persons living in Liverpool. The results from this detailed and rigorous research have major implications for cross-cultural studies. However, we are, once again, surprised to see that cases of 'conversion pseudodementia' (McEvoy \& Wells, 1979) were not detected by an epidemiological investigation. At the end of the second year of a follow-up study still in progress we confirm the diagnosis of cases of conversion pseudodementia identified at year 0 .

Briefly, our study involved review of the clinical charts of all 467 patients (228 men, 239 women; median age 49 years, range 18-93) admitted to our department of psychiatry from April 1989 to March 1990. We encountered an unexpectedly high number (six) of cases of cognitive impairment probably related to hysterical conversion reaction. This preliminary diagnosis was established using a standardised protocol based on existing sets of clinical criteria (Grant, 1989). Patient assessment followed a step-by-step algorithm: (a) recognition and measurement of the cognitive deficit by MiniMental State (Folstein et al, 1975) and Blessed-Roth information-memory-concentration test (modified by Hodkinson (1972)); (b) exclusion of organic dementing disorders by medical history, physicalneurological examination, laboratory tests, neurophysiological and brain-imaging evaluation and by 
application of the Wells' Check-List Differentiating Pseudodementia from Dementia (Wells, 1979); (c) exclusion of depression by Hamilton Rating Scale for Depression (Hamilton, 1960). The diagnosis of conversion disorder was based upon a semistructured psychiatric interview. Patient assessment also included interviews with relatives, and socioenvironment evaluations. In addition, all six patients satisfied DSM-III-R, Lazare's (1981) and Kirby \& Harper's (1988) criteria for the diagnosis of conversion disorder. The six patients identified as affected by cognitive impairment probably related to hysterical conversion reaction were included in a three-year follow-up programme. The follow-up consists of a monthly interview with patients and their relatives, a physical-neurological examination and laboratory tests every six months, and a yearly neuropsychological assessment. At the end of year 2 the outcome for the six patients was: four diagnoses of cognitive impairment definitely related to conversion disorder (one man, three women; median age 64 years; range 61-69); one diagnosis of cognitive impairment possibly related to conversion disorder (associated with depressive illness) (a 64-year-old man); one diagnosis of cognitive impairment not related to conversion disorder (diagnosis of primary degenerative dementia) (a 73-year-old man).

The relatively high number of cases of conversion pseudodementia identified by this study could possibly be related to multiple factors: (a) our apparently privileged standpoint as a result of our department being the only referral centre providing psychiatric assessment and care for the whole Val Trompia population (Brescia Province, Italy; 106244 inhabitants in March 1990); (b) a peculiar sociocultural environment able to cluster a pathology still confined to sporadic observations; (c) the possible evolution of hysterical symptoms since Charcot (1878) established the classical pathological reference patterns. In this regard it must be underlined that in the families of all four of the above-mentioned patients, at least one relative suffering from cognitive impairment could be found. The presence of affected relatives might provide a model to be mimicked. Interestingly, cognitive impairment may represent a new kind of hysterical syndrome which appears to be shaped by ageing and age-related disorders of contemporary society. Moreover, as recently speculated by Leff (1988), the expression of hysterical symptoms in the Western world has shifted from the bodily mode to the psychological mode; we believe that conversion pseudodementia might represent a paradigm of this evolution.

Although the present study is limited by the relatively small sample size and the incomplete follow-up, we would like to highlight this reversible cognitive dysfunction in order to underline the risk of an inaccurate diagnosis of dementia causing possible institutionalisation of the patient and subsequent deterioration, and to urge epidemiological research to provide quantitative data on this illness. In the light of our experience, it would be interesting to know if cases of dementia and pseudodementia, in which hysterical behaviours were identified or suspected, were detected in Copeland et al's large study.

Снаясот, J. M. (1878) Leçons sur les Maladies du Systeme Nerveux. London: New Sydenham Society.

Folstenn, M. F., Folstein, S. E. \& McHugh, P. R. (1975) “MiniMental State": a practical method for grading the cognitive state of patients for the clinician. Journal of Psychiatric Research, 12, 189-198.

GrANT, R. P. (1989) Neuropsychological assessment of dementia and related disorders. In The Diagnosis of Dementia (ed. B. L. Smith), pp. 601-634. Padova: Liviana Press.

Hamilton, M. (1960) A rating scale for depression. Journal of Neurology, Neurosurgery and Psychiatry, 23, 56-62.

HodkInson, H. M. (1972) Evaluation of a mental test score for assessment of mental impairment in the elderly. Age and Ageing. 1, 233-238.

KIRKBY, H. B. \& HARPER, R. G. (1988) Team assessment of geriatric mental patients (II): behavioral dynamics and psychometric testing in the diagnosis of functional dementia due to hysterical behaviour. Gerontologist, 28, 260-262.

LAZARE, A. (1981) Conversion symptoms. New England Journal of Medicine, 305, 745-748.

LeFF, J. (1988) Psychiatry Around the Globe. London: Gaskell.

McEvoy, J. P. \& Wels, C. E. (1979) Case studies in neuropsychiatry II: conversion pseudodementia. Journal of Clinical Psychiatry, 40, 447-449.

Wells, C. E. (1979) Pseudodementia. American Journal of Psychiatry, 136, 895-900.

PaOlo Liberini

LUCIA FAGLIA

Flavio Salvi

Department of Psychiatry

USSL 38 Lombardia

Gardone Val Trompia

Italy

Department of Psychiatry

Robert P. Grant

McGill University

Montreal

$P Q$

Canada

AUTHOR'S REPLY: Liberini and his colleagues raise interesting points in their account of the incidence of conversion pseudodementia. Within the UK, conversion hysteria is generally thought to be rare, especially in older people. A benefit of increasing interchange between European psychiatrists will be the challenging of national diagnostic customs by epidemiological evidence. 